\title{
How do Himalayan areas respond to global warming?
}

\author{
Nazzareno Diodato, ${ }^{a *}$ Gianni Bellocchi, ${ }^{\mathrm{a}, \mathrm{b}}$ and Gianni Tartari ${ }^{\mathrm{c}, \mathrm{d}}$ \\ a Met European Research Observatory, GEWEX-CEOP Network - World Climate Research Programme, 82100 Benevento, Italy \\ ${ }^{\mathrm{b}}$ Grassland Ecosystem Reserch Unit, French National Institute of Agricultural Research, Clermont-Ferrand, France \\ c Ev-K2-CNR Committee, 24126 Bergamo, Italy \\ ${ }^{\mathrm{d}}$ Water Research Institute (IRSA), National Research Council of Italy, 20047 Brugherio, Italy
}

\begin{abstract}
We study the interdecadal-scale variability over the Himalayas/Tibetan Plateau (H/TP) to deepen the understanding of Earth's important ecosystem after the recent controversy about glaciers melting in the Himalayan Mountains. We present a new statistical reconstruction of annual temperature variability back to 1901 for the Pyramid Automated Weather Station of the Ev-K2-CNR Committee, located at the base of the Mount Everest. Our reconstruction using recorded weather station data compared with the Climate Research Unit temperature pattern data indicate that in recent decades the warming trend over the H/TP has been faster than during any equivalent period in the last century. Positive temperature anomalies (mostly observed after 1970) were found to be correlated with the Atlantic Multidecadal Oscillation and the Pacifical Decadal Oscillation indices, but unevenly correlated with the Northern Hemisphere (NH) land-surface temperature. Such decoupled response between H/TP and NH suggests the mechanisms of global warming are only marginally influencing the H/TP climate. Copyright (c) 2011 Royal Meteorological Society
\end{abstract}

KEY WORDS global warming; Pyramid Automated Weather Station; teleconnection; temperature; Tibetan Plateau

Received 22 June 2010; Revised 25 October 2010; Accepted 8 March 2011

\section{Introduction}

The debate regarding the impact of anthropogenic climate change on Earth's remote ecosystems is complicated by the fact that historical weather records are limited in their length, especially at high altitudes where the sensitivity to global climatic change may be paramount (Liu and Chen, 2000; Bagla, 2009). Furthermore, large-scale orographies such as the Himalayan and Tibetan Plateau (H/TP), can also play an important role in influencing climate - most particularly with respect to monsoon circulation (Liu and Chen, 2000; Yasunary et al., 2004; Kang et al., 2010), especially by acting as an obstacle to southward flow of cool, dry air (Molnar et al., 2010).

Increases in positive temperature trends have been observed in southern pre-Himalayan areas since the 1970s (Shrestha et al., 1999), as well as over the Tibetan Plateau (TP) in more recent decades (Yimin et al., 2007; Liu et al., 2009). This may induce a faster melting of some Himalayan glaciers depending on their own individual behaviours (Inman, 2010). However, permafrost temperatures are mainly controlled by elevation and latitude (together with geothermal heat flux), and concerns are only potentially raised in relation to the possible transfert of the climate warming into permafrost temperature increases and degradation

\footnotetext{
* Correspondence to: Nazzareno Diodato, Met European Research Observatory, GEWEX-CEOP Network - World Climate Research Programme, 82100 Benevento, Italy. E-mail: nazdiod@tin.it
}

on the TP (Wu et al., 2010). Important teleconnections between El Niño-Southern Oscillation (ENSO) and temperature anomalies of the Tibetan Plateau have been temporally identified by Yin et al. (2000) and Liang et al. (2008) but, in general, temperature teleconnections are not yet well understood across Asia. This is mainly due to sparsely distributed meteorological measurement stations over such remote and mountainous areas (Xie et al., 2008). Today, the Himalayan area benefits from the recently installed instrumental observations (Ueno et al., 2008) operated by Ev-K2CNR Committee (effective in this area since 1989, http://www.evk2cnr.org, with measured data becoming available by 1994) and, in particular, from the Pyramid Automated Weather Station (hereafter Pyramid AWS), placed at the foot of Mount Everest at $5050 \mathrm{~m}$ a.s.l. $\left(86.80^{\circ} \mathrm{E}\right.$ and $\left.27.95^{\circ} \mathrm{N}\right)$.

The present study establishes the longest temperature (1901-2009) and indices series ever for this highelevation area, taking advantage of both high-resolution gridded temperature data made available by the Climate Research Unit (CRU TS3) (Brohan et al., 2006) and global datasets arranged via Climate Explorer web-GIS by both the Hadley Centre for Climate Prediction and Research and the National Climatic Data Center (van Oldenborgh et al., 2009). The annual trends in reconstructed temperature time series at the Pyramid AWS since 1901 was used to document the interdecadal-scale variability patterns over TP and to study potential temperature teleconnections. 
Table I. Availability and source of temperature datasets used for model calibration and validation, reconstruction of the temperature time series, and testing (out-of-sample validation).

\begin{tabular}{llll}
\hline Dataset & Sources & Period & Use \\
\hline Pyramid AWS & $\begin{array}{l}\text { Ev-K2-CNR Committee (Ueno } \\
\text { et al., 2008) }\end{array}$ & $1994-2001$ & $\begin{array}{l}\text { Model calibration; Temperature time } \\
\text { series reconstruction } \\
\text { Model validation; Temperature time } \\
\text { series reconstruction } \\
\text { Temperature time series } \\
\text { reconstruction }\end{array}$ \\
& $\begin{array}{l}\text { Update from Ev-K2-CNR } \\
\text { Committee (personal } \\
\text { communication) }\end{array}$ & $2002-2005$ & $\begin{array}{l}\text { Temperature time series } \\
\text { Climate Explorer (Brohan } \\
\text { et al., 2006; van Oldenborgh } \\
\text { et al., 2009) } \\
\text { NCEP NOAA-ESRL through } \\
\text { http://www.cdc.noaa.gov/cgi- } \\
\text { bin/PublicData/getpage.pl } \\
\text { Climate Explorer (van } \\
\text { Oldenborgh } \text { et al., 2009) }\end{array}$ \\
NCEP reanalysis & $1901-2005$ & $1994-2009$ & $\begin{array}{l}\text { Testing of the reconstructed } \\
\text { temperature series }\end{array}$ \\
Kathmandu WMO station & $1950-2009$ & \\
\hline
\end{tabular}

\section{Methods}

A variety of datasets was evaluated for the purposes of temperature modelling and reconstruction (Table I). In the following sections, their use is elaborated upon in detail.

\subsection{Temperature data reconstruction}

Annual temperature data for Pyramid AWS before 1994 were estimated from monthly CRU TS3 dataset (Brohan et al., 2006). An overlapping period over 1994-2005 was available with temperature records from both Pyramid AWS and the $\sim 50-\mathrm{km}$ gridded CRU TS3 dataset (available on a monthly basis). Interpolating points (longitude: $86.75-87.25^{\circ} \mathrm{E}$, latitude: $27.75-28.25^{\circ} \mathrm{N}$ ) of the CRU TS3 dataset are in the Tibetan Plateau, within a range of elevations compatible with the Pyramid AWS location. After extracting the temperature for the same coordinates of Pyramid AWS - by Climate Explorer interpolation (van Oldenborgh et al., 2009) - a relationship was found between the two series for the calibration dataset (1994-2001). From the same CRU TS3 dataset, data from 2002 to 2005 were used for validation. Monthly mean temperatures $\left(T_{m},{ }^{\circ} \mathrm{C}\right)$ at the Pyramid AWS were estimated using a linear model approximated by:

$$
T_{m}=a+b \cdot T_{m(C R U)}
$$

where $a=-3.8( \pm 0.11)$ and $b=0.75( \pm 0.02)$ are model parameters $(R=0.98)$, and $T_{m(C R U)}$ is the monthly temperature $\left({ }^{\circ} \mathrm{C}\right)$ of $\mathrm{CRU}$ TS3 dataset. Least-square regression analyses were run to estimate the parameters of Equation (1). The entire process was assessed interactively using Microsoft ${ }^{\circledR}$ Office Excel 2003 with the support of Statistics Software-R modules (Wessa, 2009).

\subsection{Evaluation of temperature series}

The estimated temperature monthly values by Equation (1) were compared against observational values.
The agreement between estimates and $T_{m}$-values was evaluated using the modelling efficiency by Nash and Sutcliffe (Nash and Sutcliffe, 1970) as performance statistic (ranging from negative to positive unity, the latter being the optimum value; positive values indicating that the model is estimating better than the average of the observed data). For a visual inspection of the quality of results, a set of comparative scatterplots and histograms (four graphs) are also presented based on temperature simulations to evaluate how the model works. A comparison against long-term records was performed using data from Kathmandu Airport, Nepal (the nearest available station), provided for 1950-2009 by the Climate Explorer database (WMO station code 44454, van Oldenborgh et al., 2009).

\subsection{Climate change investigations}

Continuous-time signals of climate change and trends in the reconstructed series were investigated by using a Morlet mother wavelet based on the same procedure described in Torrence and Compo (1998). Wavelet transforms decompose complex information and patterns into elementary forms. They are efficient in determining the damping ratio of oscillating signals and are resistant to the noise in the signal, changing adaptively to the time and frequency resolution (e.g. Ding, 2008).

The following climate indices were also used to characterize and explain the influential role of local processes and teleconnections that influence over TP temperatures: Pacific Decadal Oscillation (Mantua et al., 1997), Atlantic Multidecadal Oscillation (Goldenberg et al., 2001), and Asian-Pacific Oscillation (Zhao et al., 2007).

\section{Results and discussion}

3.1. Evaluation of reconstructed temperature data A general agreement is apparent between observed data and $T_{m}$ distributional estimates with both calibration, 

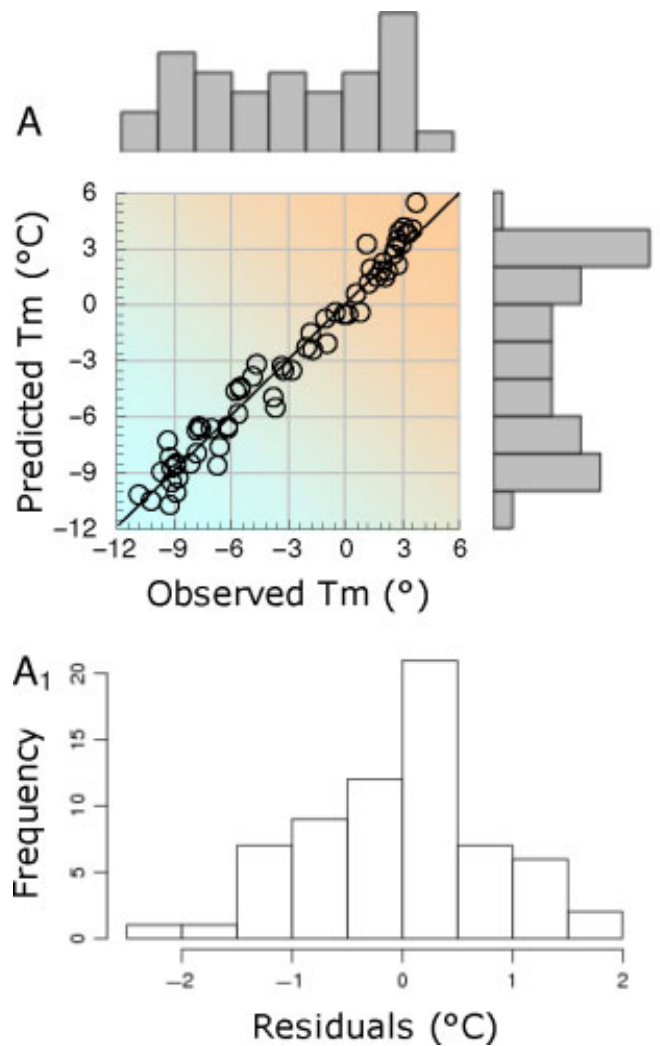
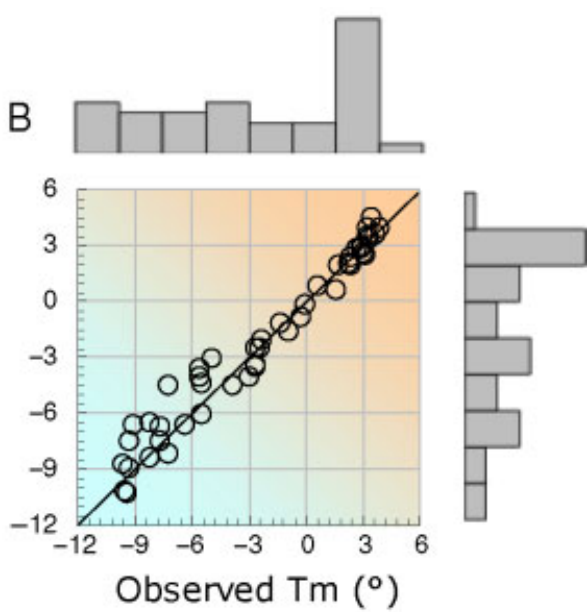

$\mathrm{B}_{1}$

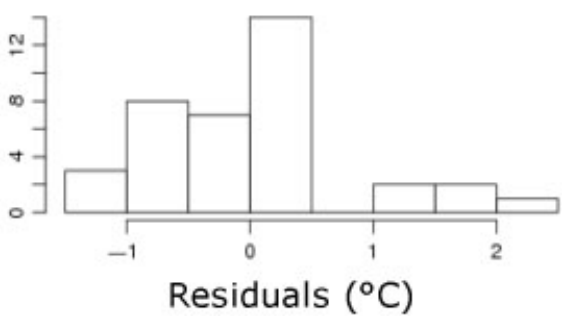

Figure 1. Scatterplots between predicted (Equation (1)) and observed montly temperature data for both (A) the calibration set (1994-2001) and (B) the validation set (2002-2005); residual distribution for both the calibration dataset (A1) and the validation dataset (B1). The 1: 1 lines are also shown in A and B. This figure is available in colour online at wileyonlinelibrary.com/journal/joc

1994-2001, and validation, 2002-2005, datasets (Figure 1 , graphs $\mathrm{A}$ and $\mathrm{B}$, respectively). Nash-Sutcliffe index of 0.97 reflects negligible departures of the data points from the $1: 1$ line. Similar values of Nash-Sutcliffe index (0.96) obtained also with validation dataset indicate certain stability in the model performance. These results also reveal a bimodal distribution in monthly temperature values (Figure 1, graphs A and B), whilst the histograms of residuals are close to quasi-normal distributions (Figure 1, graphs $\mathrm{A}_{1}$ and $\mathrm{B}_{1}$ ).

In order to verify if temperature reconstruction from monthly records was also able to capture interannual variability at the Pyramid AWS, predicted and observed annual temperatures (mean of monthly temperatures) were compared (Figure 2). The years 1994-2006 define a period of overlap with reanalysis data provided by the National Centers for Environmental Prediction (NCEP), National Oceanic and Atmospheric Administration of the United States Department of Commerce-Earth System Research Laboratory (http://www.cdc.noaa.gov).

The NCEP reanalysis represents an updated source providing relatively coarse spatial data (about $1^{\circ} \times 1^{\circ}$ ). For the period investigated, NCEP temperature fluctuations are largely approached by our reconstruction, and both series do not differ substantially from the observed profile (Figure 2, graph A).

Figure 2, graph B displays the comparison, for the testing period 1950-2009, of the predicted temperatures at Pyramid AWS and the observations taken at Kathmandu station (Nepal). The latter is placed $100 \mathrm{~km}$ apart and about $4000 \mathrm{~m}$ lower than the Pyramid station, thus, lack of correspondence between the two series is not unexpected. However, the overall trend of predicted temperatures can be considered to agree sufficiently well with the observed data series of Kathmandu. This also corresponds to the distributions of seasonal and annual temperature trends shown by Shrestha et al. (1999) for Kathmandu and high-elevation sites of the Himalayan region.

\subsection{Warming trends}

The Himalayan climate is characterized by a considerable significant temperature increase, referred to as a core of $+0.5^{\circ} \mathrm{C}$ for the period $1971-2005$ in comparison to 1901-1960 (Figure 3A 1 ). Similarly, satellite tropospheric temperature data detected from 1979 and 2007 revealed small (positive) warming trends over the $\mathrm{TP}$ compared to the strong warming trend observed in the western Himalayan region (Gautam et al., 2009), although there are major physical differences between surface and tropospheric temperatures (Parker, 2000).

Focusing on Mount Everest, Figure $3 \mathrm{~A}_{2}$ shows the temperature anomaly series for the Pyramid AWS statistically reconstructed back to 1901 using a linear regression between gridded (CRU TS3) and Pyramid AWS station data updated until 2009 (Figure 3B 1 ). The temperature series at this high elevation appear affected by an increasing trend with irregular steps and sudden shifts in amplitude that took place particularly during 

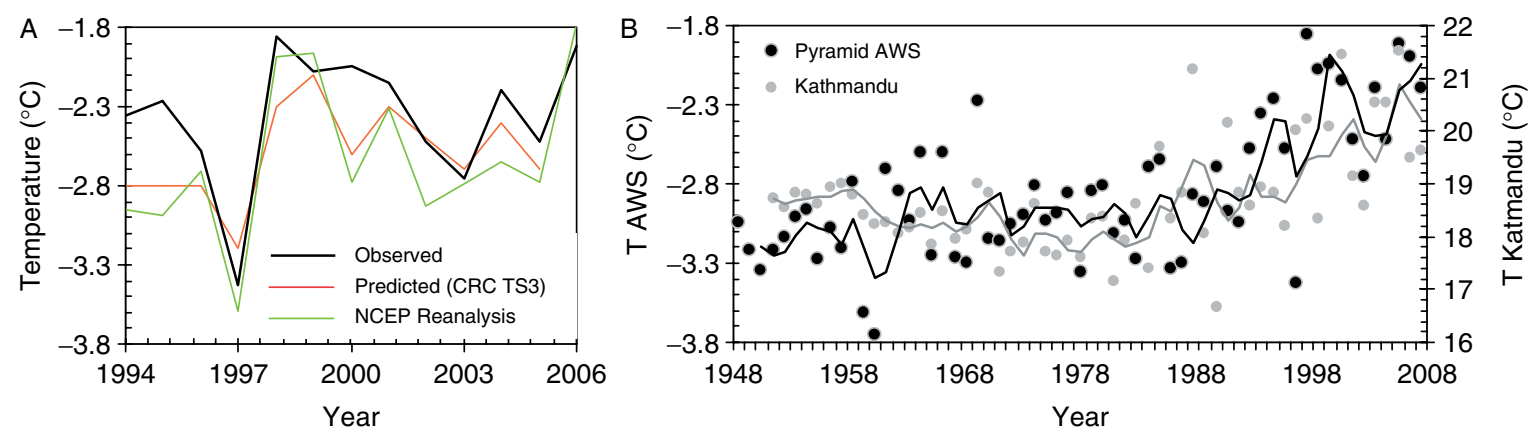

Figure 2. (A) Annual temperature as observed at the Pyramid AWS (black line), as produced from NCEP reanalysis (green line), and as predicted from CRU TS3 records (red line) for 1994-2005; (B) annual temperature as reconstructed (black data points) at the Pyramid AWS and as observed (gray data points) at Kathmandu WMO station (1333 m a.s.l.) for 1950-2009 (black and gray lines represent the respective 3 -year running means). For predictions versus Pyramid AWS observed data (graph A): Nash-Sutcliffe index $=0.39$; correlation coefficient $=$ 0.81. For predictions versus NCEP reanalysis data (graph A): Nash-Sutcliffe index $=0.72$; correlation coefficient $=0.92$. For reconstructed (Pyramid AWS) versus Kathmandu observed data (3-year running means, graph B): correlation coefficient $=0.72$. This figure is available in colour online at wileyonlinelibrary.com/journal/joc

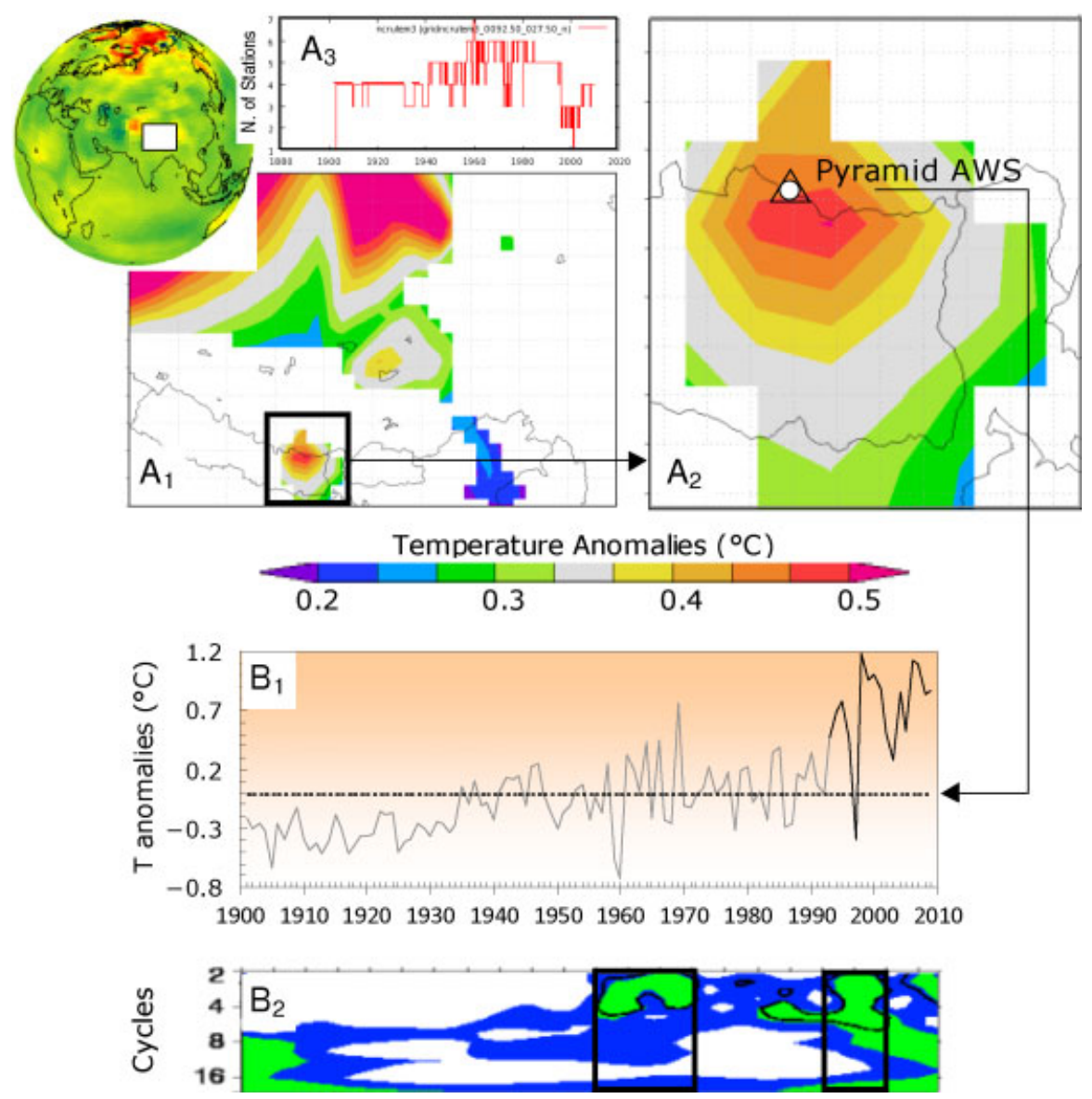

Figure 3. The study-area is marked with a white rectangle on the upper-left globe. (A1) Averaged annual temperature anomalies (1971-2006 minus 1901-1960) over the Tibetan Plateau (significant changes, i.e. $p<0.10$, are shown as a colour-coded map of the region, as arranged by CRU TS3-based Climate Explorer dataset); (A2) as in (A1) for the zoomed area around Pyramid AWS; (A3) change over time of the number of stations used in CRU TS3 dataset on the geographical window of A1; (B1) annual temperature anomalies at the Pyramid AWS (grey line indicates the reconstructed anomalies by CRU TS3 data for the years before 1994); (B2) wavelet power spectrum of the (B1) series (Torrence and Compo, 1998). This figure is available in colour online at wileyonlinelibrary.com/journal/joc

1960s and 2000s. This was also confirmed by a spectral analysis (Morlet mother wavelet), which detected two significant temperature increase trends (marked by rectangles in Figure $3 \mathrm{~B}_{2}$ ). The comparison with temperature proxy records collected in the southeast $\mathrm{TP}$ area by Yang et al. (2009) adds further confirmation to our temperature reconstruction shown in Figure $3 \mathrm{~B}_{1}$. The reconstruction performed by these authors also shows a significant warming trend after the 1950s. Although the unprecedented warming occurred during the 2000s 


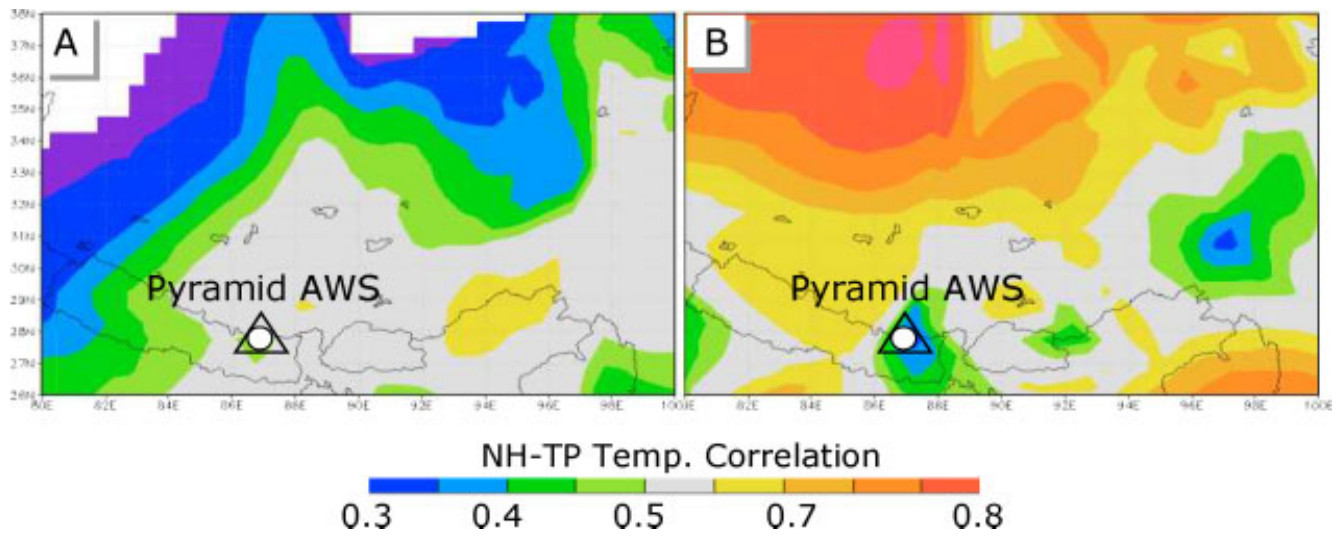

Figure 4. Spatial correlation $(p<0.10)$ between the annual temperature over the Tibetan Plateau (TP) and the Northern Hemisphere (NH) for 1901-1960 (A) and 1971-2005 (B) based on CRU TS3 (TP) and NCDC (NH) data, respectively (colour-coded map of the region as arranged by the Royal Netherlands Meteorological Institute databases and supplied by the web-GIS Climate Explorer, van Oldenborgh et al., 2009). $x$-axis is longitude, $y$-axis is latitude. This figure is available in colour online at wileyonlinelibrary.com/journal/joc

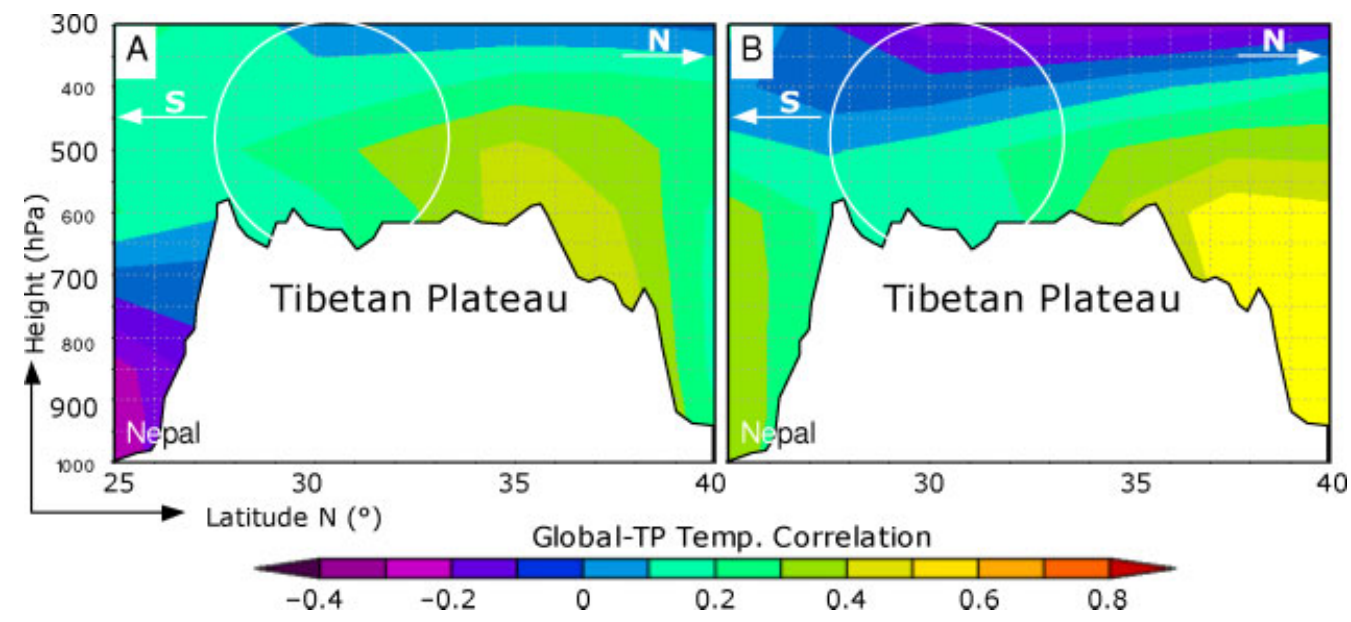

Figure 5. Correlation pattern in the latitude-height cross-section between the global warming and annual temperature over the Tibetan Plateau (TP) for (A) 1948-1970 and (B) 1971-2009, based on reanalysis data provided by the National Centers for Environmental Prediction (NCEP), National Oceanic and Atmospheric Administration of the United States Department of Commerce-Earth System Research Laboratory (http://www.cdc.noaa.gov). The area in white is the south-north Plateau section around the 90th meridian; overlying coloured zones represent the correlation patterns of the typical cross-section in the free atmosphere (the Plateau is placed around $600 \mathrm{hPa}=5000 \mathrm{~m}$ a.s.l.). This figure is available in colour online at wileyonlinelibrary.com/journal/joc

decade, several times over the past two millennia the climate was considerably warmer in the TP, and for longer periods, than during the late 20th century (Liu et al., 2002; Feng and $\mathrm{Hu}, 2005)$. Furthermore, no trend and no important changes are visible in agreement with the global warming paused over 2000-2009 (Kerr, 2009; Camuffo et al., 2010; Simmons et al., 2010; Solomon et al., 2010).

Albeit the TP is a small part of the North Hemisphere $(\mathrm{NH})$, it may respond in a different way to climate forcing (also due to its complex surrounding topography), and then it is interesting to assess the degree of teleconnections between $\mathrm{NH}$ and TP, taking advantage of both CRU TS3 and NCDC-NH (land + ocean) temperature series and TP temperature pattern. The result highlights a moderate but long and important coupling between $\mathrm{NH}$ warming and TP temperature in the period 1901-1960 (Figure 4A). This outcome is supported by a previous study performed by Bhutiyani et al. (2007) indicating, for the 20th century, similar epochs of temperature variation between global and northwestern Himalayas. Nowadays, although a coupling in the northwestern area of the TP appears clearly and with certain persistence and it can be related to global warming, at the same time, on the rest of southeastern region across the Pyramid AWS, the unvarying TP temperature with $\mathrm{NH}$ warming is an unexpected and hard-to-figure behaviour (Figure 4). It is the southeastern TP, in particular, that seems to resist the mechanisms of global warming after 1970 (Figure 4B).

This is also revealed by a correlation pattern between the global and TP temperatures in the latitude-height cross-section (Figure 5, graphs A and B), based on the NCEP reanalysis. In particular for 1971-2009 (graph B), it is visible that while temperatures to the north of the TP and in Nepal agree to the global warming (green and yellow areas), the southern part of the TP (circle) resists this global forcing, indicating the existence of different driving forces between northern and southern plateau 


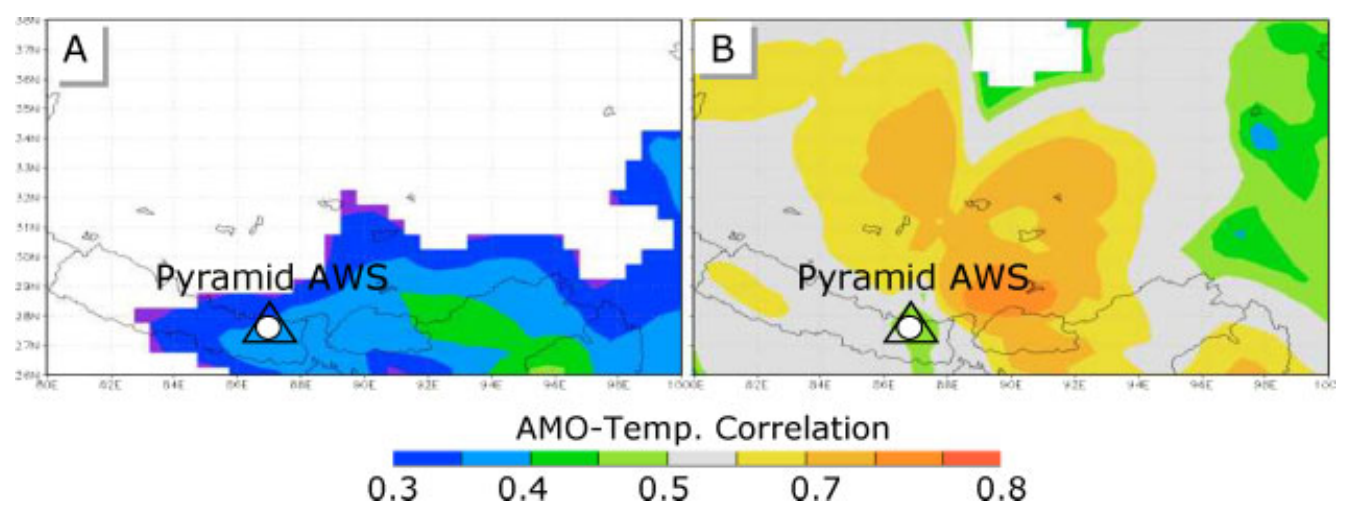

Figure 6. Spatial correlation $(p<0.10)$ between the AMO (HadSST2) and annual temperature (CRU TS3) over the Tibetan Plateau for (A) 1901-1960 and (B) 1971-2005 (arranged by the Royal Netherlands Meteorological Institute databases and supplied by the web-GIS Climate Explorer, van Oldenborgh et al., 2009). $x$-axis is longitude, $y$-axis is latitude. This figure is available in colour online at wileyonlinelibrary.com/journal/joc

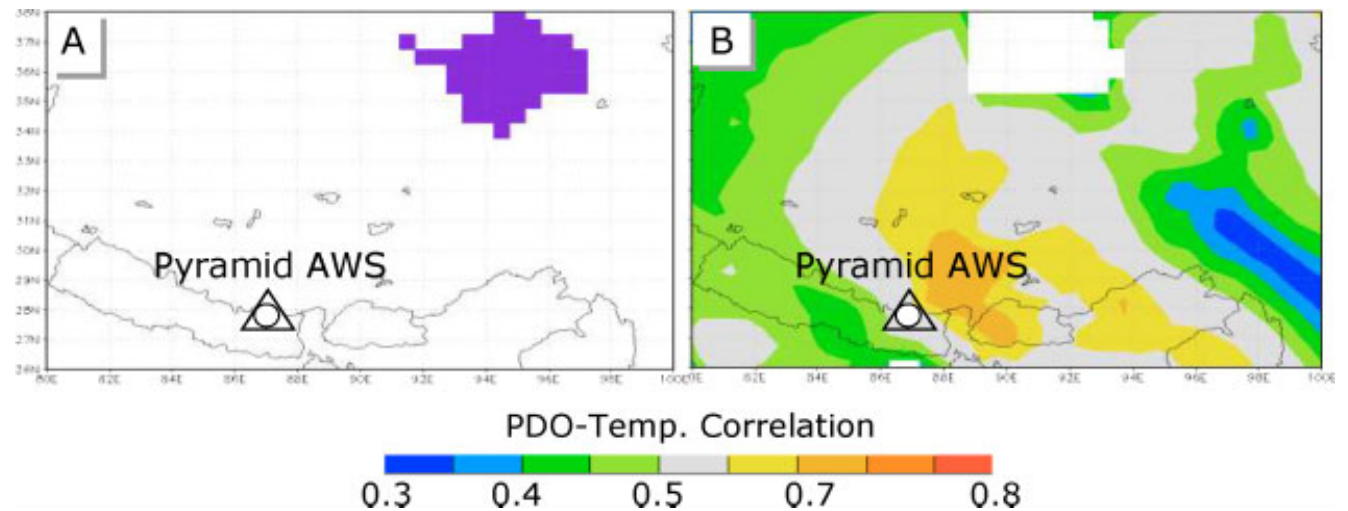

Figure 7. Spatial correlation $(p<0.10)$ between the PDO (HadSST2) and annual temperature (CRU TS3) over the Tibetan Plateau for (A) 1901-1960 and (B) 1971-2005 (arranged by the Royal Netherlands Meteorological Institute databases and supplied by the web-GIS Climate Explorer, van Oldenborgh et al., 2009). $x$-axis is longitude, $y$-axis is latitude. This figure is available in colour online at wileyonlinelibrary.com/journal/joc

zones. Not entirely supported by Shrestha et al. (1999), whose study was limited to 1971-1994, our results are consistent with an updated investigation by Ding and Zhang (2008), who found that the recent acceleration of warming in the TP has occurred later than in the north of the Yangtze River (east China), especially in winter and spring. In the recent decades, some unknown forcing working in a decoupled way, seems to have triggered the southeastern TP to depart from the $\mathrm{NH}$ climate. This decoupling emerging from the CRU TS3 estimates reveals the existence of spatial heterogeneity of regional forcing factors affecting current warming (Bradley et al., 2003).

\subsection{Temperature teleconnections}

Climate indices may influence the climate at regional scale, although areas in which important changes are detected can be scattered around the globe and lack consistency in time (Sterl et al., 2007).

The Atlantic Multidecadal Oscillation (AMO, defined from the patterns of sea surface temperatures), for instance, may have played an important role in influencing the TP climate, since it appears to be part of a wider phenomenon driven by variation in the surface heat flux and coherent with parallel fluctuations in the strength of the thermohaline circulation (Burroughs, 2003). This is indicated by a positive AMO-temperature correlation pattern, prominent and more powerful in 1971-2005 than in the previous longer period 1901-1960 when some significant correlation was already apparent limited to the southeastern TP (Figure 6A, B).

With equal emphasis and extension, a confounding change in the correlation patterns was also detected between Pacific Decadal Oscillation (PDO, detected as warm or cool surface waters in the Pacific Ocean) and temperature (Figure 7A, B), and for which a high predictability was found in relation to global climate change on decadal time scales (Mochizuki et al., 2010) as above. This was, in turn, consistent with the AsianPacific Oscillation (a zonal teleconnection pattern over the extratropical Asian-Pacific region) - which is associated with the out-of-phase relationship in atmospheric heating - and that shows a decadal variation according to the high index polarity registered before 1975 and to the low index polarity registered afterwards (Zhao et al., 2007). Conforming to the warming phase 1971-2005, the AMO and PDO effectively marked the last decades, and 
Figures 6 and 7 show that the switch of both AMO and PDO to their warm cycles from a precedent cool cycle (1901-1960) has become firmly established.

Although Sheffield and Wood (2008) found weak correlations between drought and climate indices over the warm period 1950-2000 with El Niño-3.4 and AMO, a significant correlation was found for TP temperature and AMO.

The northwestern TP is highly sensitive to global warming, while the southeastern part seems less prone to these changes. However, the relative importance of these regional factors is not clear, particularly because neither the response to regional forcing nor the regional forcing itself are well known for the 20th century (Shindell and Faluvegi, 2009). It is possible that climate-environment interactions in the Tibetan area coincide with global warming at a sub-regional level, thus leading to a speculative interpretation (Qian and Xue, 2010). For instance, You et al. (2010) suggested that change in regional atmospheric circulation is one of the important factors contributing to the recent climate warming of the TP. Considerable changes in teleconnection strength were also detected in recent decades compared to 1901-1960. Changes in cloud amount (Duan and $\mathrm{Wu}, 2006$ ) and land use (Zhang, 2007) can also be considered important factors contributing to the recent climate warming in the $\mathrm{TP}$, although local and global greenhouse gas emissions cannot be excluded. The combined action of tropospheric and stratospheric volcanic aerosols, due to their attenuation of incoming solar radiation, may also have a cooling effect on surface air temperature (e.g. Balling and Idso, 1991).

\section{Summary and conclusions}

In this study, we investigated the dynamic patterns of surface warming in the Tibetan Plateau, by correlating temperature series reconstructed in situ with large-scale (Northern Hemisphere) temperature variability. While some results seem hardly explainable, we highlight that the complex interactions between climate and temperature variability over the TP are still poorly understood and the mechanisms driving future temperature changes are not completely clarified.

The TP is located in a unique geographical zone with peculiar altitudinal characteristics and low average air temperature. Basing on our study, its climate since 1901 has changed both in time and in space indicating the non-uniform effects of global warming. Global warming started in around1850, after the end of the Little Ice Age, but its pattern could have changed character since the 1970s. The changes of air temperature in the last decades exhibit a zonational pattern not always significant. The start of a new decade (from 2010 onward) appears promising, as observed and predicted climates reveal them in a way not seen in the past 100 years. A challenge and priority for future research lies in attaining a much better understanding of what is causing the global warming. In particular, more comparative studies between different types of data sources are possible, and certainly also desirable for the reason that remote regions (such as the TP) include inhomogeneities resulting from disposal or relocation of stations and changes in the local environment. Moreover, further investigation to seasonal scales would help in the process of finding explanations for the trends and teleconnections. This will be possible as more records become available in situ, and homogenized data will be provided by the CRU TS3 on a monthly basis.

\section{Acknowledgements}

The authors are grateful to specialist colleagues Casey Saenger (Department of Geology and Geophysics at Yale University) and Carlo Casty (Risk Management and Reserves of Zürich, Switzerland) who have provided helpful comments while the research for this paper was in progress, and on draft versions of the manuscript. The authors are also grateful for the possibility offered them of using predictor data from various sources, and mainly from the Royal Netherlands Meteorological Institute (in the person of Andreas Sterl) for supplies by the Climate Explorer database. We also thank the Ev-K2CNR Committee for the use of Pyramid AWS data and the work carried out to maintain the monitoring activity in the Everest area.

\section{References}

Bagla P. 2009. No sign yet of Himalayan meltdown, Indian report finds. Science 5955: 924-925.

Balling RC Jr, Idso SB. 1991. Decreasing diurnal temperature range: $\mathrm{CO} 2$ greenhouse or $\mathrm{SO} 2$ energy balance effect? Atmospheric Research 26: 455-459.

Bhutiyani MR, Kale VS, Pawar NJ. 2007. Long-term trends in maximum, minimum and mean annual air temperatures across the Northwestern Himalaya during the twentieth century. Climatic Change 85: 159-177.

Bradley RS, Hughes MK, Diaz HF. 2003. Climate in Medieval time. Science 302: 404-405.

Brohan P, Kennedy JJ, Harris I, Tett SFB, Jones PD. 2006. Uncertainty estimates in regional and global observed temperature changes: a new dataset from 1850. Journal of Geophysical Research 111: D12106, DOI:10.1029/2005JD006548.

Burroughs WJ. 2003. Weather cycles: real or imaginary? Cambridge University Press: Edimburgh.

Camuffo D, Bertolin C, Barriendos M, Dominguez-Castro F, Cocheo C, Enzi S, Sghedoni M, della Valle A, Garnier E, Alcoforado M-J, Xoplaki E, Luterbacher J, Diodato N, Maugeri M, Nunes MF, Rodriguez R. 2010. 500-year temperature reconstruction in the Mediterranean Basin by means of documentary data and instrumental observations. Climatic Change 101: 169-199.

Ding J-J. 2008. Time-frequency analysis and wavelet transform, URL http://djj.ee.ntu.edu.tw/TFW.htm.

Ding YH, Zhang L. 2008. Intercomparison of the time for climate abrupt change between the Tibetan Plateau and other regions in China Chin. Journal of Atmospheric Science 32: 794-805.

Duan A, Wu G. 2006. Change of cloud amount and the climate warming on the Tibetan Plateau. Geophysical Research Letters 33: L22704, DOI:10.1029/2006GL027946.

Feng S, Hu Q. 2005. Regulation of Tibetan Plateau heating on variation of Indian summer monsoon in the last two millennia. Geophysical Research Letters 32: L02702, DOI:10.1029/2004GL021246.

Gautam R, Hsu NC, Lau KM, Tsay SC, Kafatos M. 2009. Enhanced pre-monsoon warming over the Himalayan-Gangetic region from 1979 to 2007. Geophysical Research Letters 36: L07704, DOI: 10.1029/2009GL037641 
Goldenberg SB, Landsea CW, Mestas-Nuñez AM, Gray WM. 2001. The recent increase in Atlantic hurricane activity: causes and implications. Science 293: 474-479.

Inman M. 2010. Settling the science on Himalayan glaciers. Nature Reports Climate Change 2010: 28-30, DOI:10.1038/climate.2010. 19.

Kang S, Xu Y, You Q, Flügel WA, Pepin N, Yao T. 2010. Review of climate and cryospheric change in the Tibetan Plateau. Environmental Research Letters 5: 015101, DOI:10.1088/17489326/5/1/015101

Kerr RA. 2009. What happened to global warming? Scientists say just wait a bit. Science 326: 28-29.

Liang E, Shao X, Qin N. 2008. Tree-ring based summer temperature reconstruction for the source region of the Yangtze River on the Tibetan Plateau. Global and Planetary Change 61: 313-320.

Liu Y, An Z, Linderholm HW, Chen D, Song H, Cai Q, Sun J, Tian H 2002. Annual temperatures during the last 2485 years in the MidEastern Tibetan Plateau inferred from tree rings. Science in China Series D: Earth Sciences, DOI:10.1007/s11430-009-0025-z.

Liu X, Chen B. 2000. Climatic warming in the Tibetan Plateau during recent decades. International Journal of Climatology 20: 1729-1742.

Liu X, Cheng Z, Yan L, Yin Z-Y. 2009. Elevation dependency of recent and future minimum surface air temperature trends in the Tibetan Plateau and its surroundings. Global and Planetary Change 68: $164-174$.

Mantua NJ, Hare SR, Zhang Y, Wallace JM, Francis RC. 1997. A Pacific interdecadal climate oscillation with impacts on salmon production. Bulletin of the American Meteorological Society 78: 1069-1079.

Mochizuki T, Ishii M, Kimoto M, Chikamoto Y, Watanabe M, Nozawa T, Sakamoto TT, Shiogama H, Awaji T, Sugiura N, Toyoda T, Yasunaka S, Tatebe H, Mori M. 2010. Pacific decadal oscillation hindcasts relevant to near-term climate prediction. Proceedings of the National Academy of Sciences USA 107: 1833-1837.

Molnar P, Boos WR, Battisti DS 2010. Orographic controls on climate and paleoclimate of Asia: thermal and mechanical roles for the Tibetan Plateau. Earth and Planetary Sciences 38: 77-102.

Nash JE, Sutcliffe JV. 1970. River flow forecasting through conceptual models part I - A discussion of principles. Journal of Hydrology 10: 282-290.

Parker DE. 2000. Temperatures high and low. Science 287: 1216-1217.

Qian L, Xue Y. 2010. Simulated impacts of land cover change on summer climate in the Tibetan Plateau. Environmental Research Letters 5: 015102, DOI:10.1088/1748-9326/5/1/015102.

Sheffield J, Wood EF. 2008. Global trends and variability in soil moisture and drought characteristics, 1950-2000, from observationdriven simulations of the terrestrial hydrologic cycle. Journal of Climate 21: 432-458.

Shindell D, Faluvegi G. 2009. Climate response to regional radiative forcing during the twentieth century. Nature Geoscience 2: 294-300.

Shrestha AB, Wake CP, Mayewski PA, Dibb JE. 1999. Maximum temperature trends in the Himalaya and its vicinity: an analysis based on temperature records from Nepal for the period 1971-94. Journal of Climate 12: 2775-2787.
Simmons AJ, Willett KM, Jones PD, Thorne PW, Dee DP. 2010. Lowfrequency variations in surface atmospheric humidity, temperature, and precipitation: inferences from reanalyses and monthly gridded observational data sets. Journal of Geophysical Research 115 D01110, DOI:10.1029/2009JD012442.

Solomon S, Rosenlof KH, Portmann RW, Daniel JS, Davis SM, Sanford TJ, Plattner G-K. 2010. Contributions of stratospheric water vapor to decadal changes in the rate of global warming. Science 327: 1219-1223.

Sterl A, van Oldenborgh GJ, Hazeleger W, Burgers G. 2007. On the robustness of ENSO teleconnections. Climate Dynamics 29: 469-485.

Torrence C, Compo GP. 1998. A practical guide to wavelet analysis. Bulletin of American Meteorological Society 79: 61-78.

Ueno K, Toyotsu K, Bertolani L, Tartari G. 2008. Stepwise onset of monsoon weather observed in the Nepal Himalaya. Monthly Weather Review 136: 2507-2522.

Van Oldenborgh GJ, Drijfhout SS, van Ulden A, Haarsma R, Sterl A, Severijns C, Hazeleger W, Dijkstra H. 2009. Western Europe is warming much faster than expected. Climate of the Past 5: 1-12.

Wessa P. 2009. Free Statistics Software, Office for Research Development and Education, version 1.1.23-r3, URL http://www.wessa.net. Wu Q, Zhang T, Liu Y. 2010. Permafrost temperatures and thickness on the Qinghai-Tibet Plateau. Global and Planetary Change 72 : $32-38$.

Xie A, Ren J, Qin X, Kang S. 2008. Pressure and temperature feasibility of NCEP/NCAR reanalysis data at Mt. Everest. Journal of Mountain Science 5: 32-37.

Yang B, Bräuning A, Liu J, Davis ME, Yajun S. 2009. Temperature changes on the Tibetan Plateau during the past 600 years inferred from ice cores and tree rings. Global and Planetary Change 69: 71-78.

Yasunary T, Abe M, Kitoh A. 2004. Evolution of the Asian monsoon and the coupled atmosphere-ocean system in the tropics associated with the uplift of the Tibetan Plateau - A simulation with the MRI coupled atmosphere-ocean GCM. Hymalayan Journal of Sciences 2: 282-283.

Yimin L, Qing B, Anmin D, Zheng'an Q, Guoxiong W. 2007. Recent progress in the impact of the Tibetan Plateau on climate in China. Advances in Atmospheric Sciences 24: 1060-1076.

Yin Z, Lin Z, Zhao X. 2000. Temperature anomalies in central and eastern Tibetan Plateau in relation to general circulation patterns during 1951-1993. International Journal of Climatology 20: $1431-1449$.

You Q, Kang S, Pepin N, Flügel W-A, Sanchez-Lorenzo A, Yan Y, Zhang Y. 2010. Climate warming and associated changes in atmospheric circulation in the eastern and central Tibetan Plateau from a homogenized dataset. Global and Planetary Change 72: $11-24$.

Zhang T. 2007. Perspectives on environmental study of response to climatic and land cover/land use change over the Qinghai-Tibetan plateau: an introduction. Arctic, Antarctic, and Alpine Reseerch 39: $631-640$.

Zhao P, Zhu Y, Zhang R. 2007. An Asian-Pacific teleconnection in summer tropospheric temperature and associated Asian climate variability. Climate Dynamics 29: 293-303. 